\title{
Cultivation and Innovation: Chinese Excellent Traditional Culture and Sinicization of Marxism
}

\author{
Jingkang Yu \\ Party School of the Sichuan Provincial Committee of the Communist Party of China, \\ 56 Guanghua Village Street, Chengdu, Sichuan, China
}

\begin{abstract}
China's excellent traditional culture has its own intrinsic value, in the process of Marxism in China, the Chinese communists will Marxist theory and this value combined, not only makes the value of China's excellent traditional culture to the extreme, but also to their own development added new elements and vitality; Marxism was introduced into China and became Sinicized Marxism. From the perspective of culture, it mainly benefited from the cultural soil and cultural context provided by the excellent traditional Chinese culture, which enabled the Chinese people to understand and disseminate the content of Marxist theory through various forms and channels. The excellent Chinese traditional culture has made its own contribution to the development of Sinicization of Marxism, which also provides a good opportunity for inheriting and developing the excellent Chinese traditional culture.
\end{abstract}

Keywords: Chinese Excellent Traditional culture, Sinicization of Marxism, The spirit of the Chinese Nation, Inheriting the Development.

\section{Introduction}

With the development of society and economic growth, people's understanding of traditional culture and their ability to distinguish foreign cultures have improved significantly. In the past, we have studied more about how to treat traditional Chinese culture and how to treat foreign cultures. What kind of attitude and principles should be adopted to promote Chinese culture, then it is very necessary to put forward the specific concept of Chinese excellent traditional culture and explore its integration with advanced foreign culture. By exploring the relationship between the two, we can better understand the specific outstanding cultures in Chinese traditional culture, and whether these contents have any enlightenment for the development of today's society; at the same time, we are concerned about the outstanding civilization achievements we have introduced from abroad. What kind of attitude should we treat and how we should integrate it into China's mainland and realize localization and nationalization in China. This provides an example for us to study how to integrate Chinese local culture with foreign culture.

\section{The Contemporary Value of Chinese Excellent Traditional Culture}

2.1 Understanding its Characteristics from the Perspective of Production and Development

The excellent Chinese traditional culture has a long history, broad and profound. Chinese culture was born in the relatively independent East Asian continent. In the process of development, although China has undergone many dynasties changes, it is rarely invaded and interfered by foreign countries and affected by its geographical location. Chinese culture is relatively independent. Features. At the same time, due to the inclusiveness and openness of the development of the Chinese nation, the development of Chinese culture, along with the accumulation of the Chinese people in the past dynasties, presents the characteristics of a long history, extensiveness and profoundness. The excellent Chinese traditional culture is a cultural treasure house including Confucianism, Chinese philosophy, traditional virtues, national spirit, revolutionary culture, poetry, esthetics, astronomy and geography, etc. It can be seen that its contents include politics, ethics, Economics and other aspects. Unlike other ancient civilizations, Chinese culture has continued to develop without interruption. This is also its unique quality among the four ancient civilizations. In modern society, we are increasingly emphasizing the inheritance and promotion of excellent traditional culture. Under the call of the party's policy, and in the cultural identity of the Chinese sons and daughters, Chinese culture will surely get a new round of development.

Chinese excellent traditional culture is deeply ingrained in the land of China in practice. More than 2,000 years ago, great thinkers such as Confucius, Mencius, Laozi, and Zhuangzi were born in China. For a time, there was a grand occasion of "a hundred schools of thought contend for a hundred flowers" in the intellectual circle of China. The concepts of propriety, wisdom, faith, rule by inaction, nature, harmony between man and nature, and the rule of law still affect the production and life of people in China and the world. The breadth and depth of Chinese excellent traditional culture is not only reflected in its early generation and long duration, but more importantly, its role in the country and society during its development is also deeply rooted. As the saying goes, "Half of "The Analects of Confucius" governs the world", which is enough to show how unpredictable the wisdom of ancient people is from the perspective of today's society. General Secretary Xi Jinping is a leader who is very good at using allusions. Whether in international or domestic meetings, we often hear idioms, allusions, poems, etc. from General Secretary Xi's hand. The reason lies in the wisdom in it. It is valuable, especially in the governance of the country, and it can give us a lot of enlightenment. 


\subsection{Understanding its Value from the Perspective of National Soft Power}

Enhance the source of cultivation of national cultural soft power. At present, our country is undergoing "big changes unseen in three thousand years" for centuries. The trend of globalization has become more obvious. The competition among countries in the world has become more and more fierce. Under such circumstances, cultural elements have become more and more masters. An important bargaining chip for the right to speak, the country's cultural soft power has also emerged, which is also a new category proposed by our leaders in response to the new changes in peace and development. Throughout the world, in addition to the two hard powers of economy and military, the improvement of cultural soft power is regarded as an important way to enhance the country's comprehensive strength. The development of a country's cultural soft power depends to a large extent on the country's cultural national conditions. Among the countries in the world, only the Chinese civilization has never been interrupted and has been renewed with vitality and vitality during thousands of years of development. The improvement of China's cultural soft power is sometimes mainly due to its uninterrupted history of civilization after thousands of years. In China, its excellent traditional culture can provide it in the course of its political development, economic prosperity, military strength, and educational improvement. Enlighten and help. The development of modern and contemporary Chinese society can be inspired by the long river of Chinese historical development.

The supporting point for the Chinese nation to stand among the nations of the world. Cultural soft power is related to the international status and influence of a nation in the global cultural structure. Among the many countries and nations in the world, the Chinese nation is like a dazzling pearl that attracts people's attention. Around the Party Central Committee, in the great practice of reform and opening up, inherit and innovate the excellent traditional Chinese culture. Therefore, the Chinese nation has strong vitality and influence, and the Chinese nation can stand tall among the nations of the world. Mr. Qian Mu said: "Chinese culture is not only created by the Chinese nation, but Chinese culture can create the Chinese nation and become a unique nation in the history of the world."[1] A large part of the credit for China's ability to grow from weak to strong lies in its profound cultural heritage. The culture of a country is the content of the field of social consciousness, and the spiritual inheritance of Chinese culture has a great stimulating effect on the practical struggle of the Chinese people.

Propeller to realize the Chinese dream of the great rejuvenation of the Chinese nation. The Chinese Dream is an important political concept put forward by Comrade Xi Jinping when he took office. It is to realize the great rejuvenation of the Chinese nation. This is not only the mission of every Chinese Communist, but also the wish of every Chinese son and daughter. The prosperity of the nation and the prosperity of culture proceed simultaneously. Looking back at history, during the heyday of the Tang Dynasty,
Chinese culture can be said to have developed to the extreme. At that time, no one dared to commit a crime in all nations. Closed and locked in the country, standing still, ideologically imprisoned, and cultural development stagnated, the door of China was finally blasted open by the British, the Eight-Power Allied Forces invaded China and burned the Old Summer Palace. A series of blood and tears made the Chinese learn "the lesson that backwardness is bound to be beaten." However, today, our national strength is so strong that no one dares to commit crimes, but we have to think about dangers and continue to strengthen ourselves so as to restore the Chinese nation to its former glory. The realization of the Chinese Dream requires both the development of material civilization and the coordinated development of spiritual civilization. The excellent Chinese traditional culture is a booster to promote the development of spiritual civilization. We need to find cultural consciousness in the excellent Chinese traditional culture. We must also carry forward the excellent Chinese traditional culture while inheriting the national spirit to help realize the Chinese dream.

\section{The Scientific Connotation of the Sinicization of Marxism}

\subsection{The Era Background of the Sinicization of Marxism}

The era background of Marxism entering China. As a kind of ideology, culture and ideology, Marxism was born under the historical background of the European Renaissance, Enlightenment and the integration of Eastern and Western thoughts. It is the first modernization of human history in Western Europe, which represents the stage of capitalist industrialization. The ideology of the new proletariat. Therefore, Marxism is the master of modern civilization created by absorbing and transforming all the valuable elements in the history of human culture and ideological development. The introduction of Marxism into China started with the revolution of the Chinese people. While the strong ships of imperialism opened the door to China, it also brought us advanced Western ideology and culture. After the Chinese Communists used Marxism to guide the Chinese revolution to victory, they established a new China, and after difficult and tortuous exploration, pioneered the path of socialism with Chinese characteristics.

The background of the Chineseization of Marxism Due to the special national conditions, the aggression of modern imperialism, and the subsequent collision and exchange of Chinese and Western cultures, the revolution faced by modern China is comprehensive. Political revolutions, ideological revolutions, cultural revolutions, etc. have followed one after another, and it has been managed for five thousand years. China's civilized history, but facing the complicated revolutionary problems of the revolution, the Chinese Communist Party will still make dogmatic mistakes, fail to solve the "Left" and "Right" issues, and face the relationship between traditional culture and foreign culture. How should they be treated? These issues have been plagued by revolutionaries for a long time. Comrade Mao Zedong combined the ancient Chinese philosophical theories, 
summed up China's long-term revolutionary practical experience, and reflected on the problem. Comrade Mao Zedong clearly put forward the scientific proposition of "Marxism Sinicization". Although Marxist theory is a scientific theory, it has a guiding role for the international communist movement, but Chinese people's problems must be solved by Chinese methods, and more importantly, they must be transformed in light of actual conditions. Therefore, Marxism should Rooted in China's excellent traditional culture, it should be endowed with the characteristics and style of the Chinese culture.

The practical significance of Sinicization of Marxism. When Marxism was first used to guide the Chinese revolution, the Chinese often copied its doctrines. Perhaps it was because the "lion" in China had fallen asleep for too long, and could not adapt to many new things for a while, so it was a crime. The mistakes of bookishism have caused the revolutionary road to be full of hardships. It is precisely because of this that the revolutionaries understood that the use of digging culture should be combined with China's national conditions. China, as an ancient civilization, under the rule of feudal autocracy, the small peasant economy has long occupied a dominant position, the feudal culture and thoughts are deeply rooted, and it has a special national background. China's national conditions determine that China will take the road of revolution in order to achieve rapid and stable social development. Practice has proved that Marxism not only provides a methodology for solving problems, but also becomes the starting point for in-depth research. It understands the world around it from practice, takes practice as the basis of all knowledge, and is the theory of development.

\subsection{The Combination of Marxism and China's Specific Practical Content}

Integrate with Chinese revolutionary practice. During the revolutionary period, China, which has experienced historical trauma since modern times, is still trying its best to find a way out for its revival and development. After various attempts and encounters, a group of advanced intellectuals such as Chen Duxiu and Li Dazhao summed up the experience and lessons of the May Fourth Movement, and learned from the experience of the Russian October Revolution to face the coming world and various ideas. The theory has chosen Marxism resolutely for China, which is waiting to be rejuvenated. It also brought China's emerging proletariat to the stage of history as an independent political force, and during this period enabled Marxism to be widely spread in China.

Integration with socialist construction. During the construction period, the development of New China achieved certain results. The basic principles of Marxism were combined with the specific practical problems in the initial exploration of China's social construction, which clarified the direction and provided action guidelines for China's socialist transformation. Combining the characteristics of the long-term formation and structural complexity of the various social classes in the early days of New China, and comprehensively using the guiding ideology of Marxism-Leninism, the Chinese Communists, with Comrade Mao Zedong as the main representative, actively explored how Chinese society changed from capitalism to capitalism. The proposition of socialist transition has developed into a long-term transitional social proposition that fits China's reality and has unique Chinese characteristics, and the general line of "one transformation and three reforms" and the general tasks and other theoretical results.

Integrate with China's reform practice. The practical process of any theory is not smooth sailing, and the value of any theory can only be continuously broken through and perfected if it originates from practice, develops in practice, and is tested in the course of practice. The opening of the reform period of New China came under the background of the continuous emergence of a series of social contradictions in the latter part of the construction period. The new generation of leaders represented by Deng Xiaoping used a keener overall development perspective, starting from the two major international and domestic environments. On the one hand, they conducted a rational analysis of the domestic problems that occurred in the later stages of the construction period, and scientifically and meticulously summarized them. Development lessons, and accurately grasp the development potential of China in the new era, and put forward various plans; on the other hand, combined with the international background of the global development trend, China is required not only to reform, but also to open up. Under the lessons of the consequences brought about by "Yelang arrogance" and "closing the country", we must actively follow the pace of the times and open up in all aspects of economy, politics, and culture. China's socialist reform was collectively called by Comrade Xi Jinping as a great social revolution. It can be said that the thinking of reform and opening up was largely inspired by the development of Marxism.

\subsection{The Combination of Marxism and Chinese History and Culture}

Necessity analysis. Marx and Engels criticized and inherited the bourgeois doctrine, combined with the development of the socialist movement to form another ideology, which is Marxism. This process shows that the birth of a new ideology is inseparable from the inheritance and development of the existing ideology. In the same way, after the introduction of Marxism into China, if you want to use it for your own use, you need to integrate it with Chinese history and culture. This is also a very important aspect of the Sinicization of Marxism. For a long time, Confucian culture has dominated the ancient society of our country, and Confucian people-oriented ideas have been adopted by the rulers for a long time. Under such circumstances, how difficult is it for Western democratic ideas to be introduced into China? Woolen cloth? Regardless of whether it is Chinese people-oriented thinking or Western democratic thinking, although the two have certain differences in form and essence, they are both a form of democracy for the ruled, and they can naturally accept. 
Possibility analysis. Marxism can be combined with Chinese history and culture because of the similarity between Chinese and Western cultures. At the beginning of the introduction of Marxism into China, it was still a completely new concept for the Chinese in the early 20th century. Due to the differences in language and culture, and because they did not know much about the world outside of China, it was still a good idea to understand this concept. There is a certain degree of difficulty. The reason why Marxism can be widely spread in China is also due to the fact that the intellectuals of the time used Chinese easy-to-understand language to translate for the public. The content of Marxist theory is similar to the content of Chinese philosophy and Confucianism. Marx has dialectical materialism, and Chinese philosophy also has the origin of dialectics. Marx emphasizes the vital interests of the working class. Chinese Confucianism also emphasizes people-oriented idea. In view of this, it is well understood that Mr. Guo Moruo wrote in his essay "Marx's into the Confucian Temple": "Marx (to Confucius) said: 'I didn't think two thousand years ago, in the far east, there was such a thing as you. An old comrade, you and I have exactly the same opinion'.’[2]

\section{The Contributions of Chinese Excellent Traditional Culture to the Sinicization of Marxism}

\subsection{Chinese Excellent Traditional Culture Provides Cultural Soil for the Sinicization of Marxism}

Chinese cultural context as a natural background. Marxism was born in Europe in the 1840s and is an important part of Western civilization; Chinese excellent traditional culture was born in Asia 5,000 years ago and is an outstanding representative of Eastern civilization; in terms of time, the emergence of Chinese excellent traditional culture is far Earlier than Marxism, Marxism needs to be cultivated in the fertile soil of Chinese culture in order to realize the Sinicization of Marxism, because Chinese excellent traditional culture has a language environment for dissemination and expression in China. Although in the Ming and Qing Dynasties, the policy of shutting down the country gave the appearance that the door to Chinese culture had been closed, but in fact the closure was only a relative closure. If it was really closed, how could it give foreign invaders a chance? On the contrary, China's cultural gates have always been open to the outside world. This can be illustrated by Zheng He's voyages to the West in the Tang Dynasty, the visit of Christianity in the Yuan Dynasty to China, and the visit of the Church of Jesus in the Ming and Qing Dynasties. Since ancient times, Chinese people have the attitude of "inclusive of all rivers, tolerance is great", and their acceptance of foreign cultures has shown great tolerance. Chinese traditional cultures such as Confucian culture and philosophical culture have experienced thousands of years of accumulation and learned from each family. Long and integrated, of course, we will not shut out the excellent civilization of Marxism.
Chinese mainstream culture provides forms of expression. The main method of expressing Marxist thought and spreading Marxism in Chinese language is to use China's native cultural resources and language environment to transform Marxism from Western civilization to Eastern culture. Deng Xiaoping said: "It is also necessary to adopt the old form to reflect the new content, because the old form has deep-rooted potential among the people, is deeply loved by the masses, and has its own useful value."[3] For example, Chinese idioms are well-organized and concise; Chinese fables are short, lean and easy to understand; Chinese colloquial languages are even more diverse and countless, all of which can be used as a form of presentation of the achievements of Marxism in China. In contemporary society, with the development of science and technology and the attention of the propaganda department, more Marxist-related film and television works, such as "Young Marx" and "Leader", are also presented on the big screen.

Chinese traditional thinking provides understanding thinking. In any piece of land or a country, it is almost impossible for the entry of foreign culture to succeed through the method of overall transplantation, and the realization of Marxism in China is naturally no exception. Two different civilizations have met and merged, and the process that needs to be experienced during this process is probably a process of collision, exchange, reference, and integration. An important prerequisite for this process is that the cultural context of the implantation place can be shared with foreign cultures. Place. Western democracy was introduced into China, and the Chinese gave its essential connotations to Chinese people-oriented thinking. This is the way for the two ideas to develop separately, and it is also the main method for Western civilization to be introduced into the East and presented to the world. Incorporating new ideas and new ideas into the existing way of thinking, mainstream media propaganda through corresponding forms to make them reach the status of mainstream cultural awareness.

\subsection{The Chinese National Spirit Adds Spiritual Motivation to the Sinicization of Marxism}

Great creative spirit is the foothold. If any nation lacks creativity and does not pay attention to the cultivation of the creative spirit, it will not be able to achieve substantial and stable development on the world stage. Especially in the context of the era of faster and faster information changes, the great creative spirit should always be emphasized. The great creative spirit not only stops at the continuous excavation of its own potential, it also emphasizes the need to actively learn from the power of excellent foreign cultures, so as to promote the spread and development of the creative spirit around the world. The practice and development of the theory of Marxism Sinicization is based on drawing lessons from foreign excellent cultures and further forming and growing through the exploration of its own potential.

The great spirit of struggle is the starting point. There is no 
achievement at your fingertips in the world, and the best way to achieve achievement is to struggle. But the process of struggle is generally not smooth sailing, and requires many tests and experiences. Struggle is the starting point and hardship is the guarantee. From the perspective of the entire development process of Marxist theory from being introduced to China, to being selected by China, and then to being used, transformed and innovated by China, the result is beautiful, but the process is difficult. From the fact that it was not recognized and accepted by the Chinese people at the beginning, to the emergence of a series of social contradictions in the middle period, and the summary of these lessons that some aspects of the problem still cannot be effectively resolved, it can be seen that the development of Marxism in China needs to be carried forward. A great spirit of struggle requires the confidence and determination to work hard to be on the road forever.

The great spirit of solidarity is the supporting point. The spirit of solidarity emphasizes the thinking of recognition, acceptance and cooperation. For the development of any theory, in addition to excellent leaders, more solid strength comes from the support and support of the broad masses of the people. China has hundreds of millions of people. This is a team with huge numbers and great potential. If used well, it can accomplish the miracle of the world, and it will be destroyed if it is not grasped properly. Marxism can take root and sprout smoothly in China and grow into the towering tree today, not only because it is a correct theory, but also because it is recognized and promoted by hundreds of millions of Chinese people.

The spirit of great dreams is the place to stay. The great dream spirit is an excellent gene in Chinese excellent traditional culture. It is full of Chinese people's longing and yearning for all the beautiful things in the future society. Since ancient times, the development of the Chinese nation has gone through vicissitudes of life, and the difficulties and obstacles encountered are countless; during the period of revolutionary construction, the revolutionary conditions of the Communist Party of China were extremely difficult, and the problems faced by the socialist construction exploration were endless; during the period of reform and opening up, the Communist Party of It is difficult under the conditions of the times. The Sinicization of Marxism is a long process. From the beginning of the 20th century to the present, it has been a century. During this period, there were doubts about foreign culture and confusion about how to view traditional culture, but these have not become China. The people's troubles, even though they have gone through detours during the period, finally returned to the right path, because the great dream spirit has provided us with the right direction.

\section{Sinicization of Marxism Promotes the Inheritance and Development of Chinese Excellent Traditional Culture}

5.1 A Series of Achievements of the Sinicization of Marxism Give New Era Connotations to Chinese Excellent Traditional Culture
Mao Zedong Thought's new development of Chinese excellent traditional culture during the period of revolutionary construction. The series of social changes triggered by the introduction of Marxism into China are practices that have never been seen in China, a land with a history of five thousand years of development. The introduction of Marxism theory has injected new blood into the development of Chinese history. The content of Mao Zedong Thought embodies the combination of Marxism and Chinese excellent traditional culture in three aspects, one is the combination with Chinese philosophy, the other is the combination of the ideological line level and the practical work level. The creative transformation and innovative development of Mao Zedong Thought to the excellent traditional Chinese culture is mainly reflected in the combination of Marxist theories with Chinese philosophical theories. Mao Zedong Thought was formed and developed on the basis of drawing lessons from the important theories and works of Marxism, combined with the actual development of China and the background of excellent Chinese traditional culture. It is one of China's important ideological and theoretical achievements since the founding of New China. In Mao Zedong's "On Practice”, "On Contradiction" and other works, the "knowledge and action unity", "dialectical unity" and other viewpoints fully reflect the author's way of thinking that closely links Marxist theory with Chinese excellent traditional culture. The wave of historical development has proved to be an ideological treatise with positive practical significance.

The new development of Chinese excellent traditional culture by the theory of socialism with Chinese characteristics in the period of socialist modernization construction. Xi Jinping pointed out: "The entry of Marxism into China has not only triggered a profound transformation of Chinese civilization, but also has gone through a process of gradual Sinicization."[4] China's excellent traditional culture has always been an important source of thought that cannot be ignored in the progress and development of the Chinese nation. China is also based on the experience of "taking the essence and removing the dross" and combining Marxist theories to continuously enrich and innovate the advanced socialist culture. How to use Marxist theories to tell the story of the Chinese people's own development? It means that after a deep understanding of Marxist theories, it is necessary to use the traditional excellent culture that the people are familiar with and empathize with, combined with China's reality, and translate it into hundreds of millions of people. He can hear clearly and understand the language form, which in a certain sense has realized the new development of Chinese excellent traditional culture. The theory of socialism with Chinese characteristics is the main content of advanced socialist culture. These contents cover the economic, political, cultural, military, educational and other aspects of contemporary socialist development. They not only reflect the rich contents of contemporary civilization, but also integrate Chinese culture into the great struggle of the new era and endow Chinese culture. Rich language of the times. The theoretical system of socialism with Chinese characteristics is presented in today's society in the form of Chinese style, Chinese style, Chinese discourse, Chinese schemes, etc., inheriting and 
carrying forward the language expression form and text presentation form of the excellent traditional Chinese culture, and realizing the internalization of the excellent traditional Chinese culture. New developments outside.

\subsection{Sinicization of Marxism Promotes the Inheritance and Development of Chinese Excellent Traditional Culture}

The interaction and integration of the Sinicization of Marxism and the excellent Chinese traditional culture to promote cultural inheritance and development. Marxism in China can be successfully realized in China because the Marxist content can find a budding point that fits with the excellent Chinese traditional culture. In terms of time, the excellent Chinese traditional culture is a product of history. If it is to be developed, it must be injected New vitality, and the Sinicization of Marxism is just a source of vitality that can give new elements to traditional culture. Marxist theory is a spiritual wealth with rich connotations, profound thoughts and a huge system. It has a distinctive contemporary character and vigorous vitality. The excellent Chinese traditional culture is created, inherited and evolved by the Chinese people on the basis of the five thousand years of development of the Chinese nation. It has a unique historicity and infinite tolerance. It is precisely because of the shining characteristics of the two, as well as the mutual communication and integration of the characteristics, that lead and promote the two to discover each other, recognize each other, and achieve each other. Since the 1990s, China's history of accepting Marxist theory shows that whether it is in inheriting tradition or innovating and creating content, the Sinicization of Marxism and the excellent traditional Chinese culture have achieved an organic combination and mutual achievement. Especially in the wave of great development in the new era, the concepts such as the "Chinese Dream" and the "Community of Shared Future for Mankind" have been put forward to concretize and practice the interaction of the two. From the perspective of Marxist theory, this is a concretization of the ideals of communism. The results show that the theoretical results of the Sinicization of Marxism have absorbed the beneficial results related to the concept of practice, dialectics, history, and morality in Chinese culture, and have achieved a new round of development of Chinese culture.

The Sinicization of Marxism opens up a path for the inheritance and development of Chinese excellent traditional culture. The process of human history should be viewed dialectically from a historical and developmental perspective. This is an important ideological statement of Marxist theory. Under the background of the new era, the inheritance, development and innovation of Chinese excellent traditional culture will always in-depth study, research and exploration of more valuable practical theories in Marxist theories, so as to promote China in the new era to continue to realize the Chinese dream of great rejuvenation. struggle. In order to realize the inheritance and development of Chinese culture in the process of Sinicization of Marxism, we must do the following: one is to inherit and develop the excellent traditional Chinese culture under the leadership of the Communist Party of China; the other is to communicate with the new era. Combining the great practices of socialism with Chinese characteristics; third, we must uphold the guiding position of Marxism in the field of ideology in our country; fourth, we must base ourselves on the local and face the world, and achieve innovative development while absorbing the nutrients of various civilizations. In short, the inheritance and development of our excellent Chinese traditional culture is to continuously inject fresh elements and new blood into the practice of Marxism in China. Only in this way can we keep pace with the times, maintain vigor and vitality, and become the Chinese people. Cultural self-confidence is an important cultural resource.

\section{Conclusion}

In-depth study of the internal connection between the excellent Chinese traditional culture and the Sinicization of Marxism can deepen the understanding of the contemporary value of the excellent traditional Chinese culture, make better use of its nourishing effect on the Sinicization of Marxism, and give better play to it. The guiding role of Marxism in the field of China's ideology is conducive to promoting the creative transformation and innovative development of Chinese excellent traditional culture, and it also gives Chinese excellent traditional culture new connotations of the times. The interaction between the Sinicization of Marxism and the excellent Chinese traditional culture has promoted the inheritance and development of Chinese civilization and is of great significance to cultural innovation.

\section{References}

[1] Qian Mu. Twelve Lectures on Chinese Culture[M]. Beijing: Jiuzhou Publishing House, 2012.

[2] Guo Moruo's book publishing Committee. The Complete Works of Guo Moruo (Literature Edition) Volume 10[M]. People's Literature Publishing House, 1985 ,

[3] Document Editing Committee of the CPC Central Committee. Selected Works of Deng Xiaoping (Volume 1) [M]. Beijing: People's Publishing House, 1994:54.

[4] Xi Jinping's speech at the Symposium on Philosophy and Social Sciences[N]. Xinhua News Agency, 2016-05-17.

\section{Author Profile}

Jingkang Yu, male, born in 1995, a master's degree candidate at the Sichuan Provincial Party School of the Communist Party of China, research direction: theory and practice of socialism with Chinese characteristics. 